\title{
The two-hit hypothesis and paraganglioma of the head and neck
}

The article on management of head and neck paraganglioma ${ }^{1}$ in this month's Journal of Laryngology \& Otology is being published on the first anniversary (10 July 2017) of the passing away of Alfred G Knudson, the architect of the two-hit theory, ${ }^{2}$ fundamental to our understanding of tumour genetic mutation. This theory explained, for the first time, among other matters, why some develop a tumour early in life and others late. As tumours are the result of accumulated mutations to a cell's $\mathrm{DNA}^{3}{ }^{3}$ it follows that one born with a single mutation needs a second 'hit' for a tumour to occur, and another born without mutation requires two hits, reflecting a play betwixt germ line and somatic mutation. We honour Alfred G Knudson (born 1923), who worked at the Fox Chase Cancer Centre Philadelphia, for his work that led to the concept of tumour suppressor genes.

As our understanding of head and neck paraganglioma increases, we realise that surgery, which has long been the mainstay of treatment, is no longer so. This is not to say that surgery is out, but management is tempered by advances in genetics, improvements in diagnostic imaging and the longitudinal behaviour of these tumours. ${ }^{4}$ A quarter of patients with head and neck paragangliomas harbour predisposing genetic mutations. ${ }^{5}$ SDHD mutations were found in all patients with familial head and neck paraganglioma in a paper from Belgium. ${ }^{5}$ In sporadic cases, the prevalence of SDHB mutations was twice that of SDHD mutations. Patients harbouring SDHB mutations had unilateral late-onset head and neck tumours, without evidence of recurrence or malignancy.

The work by Harrison and Corbridge, ${ }^{1}$ on active surveillance of head and neck paragangliomas over a fiveyear period, demonstrates the favourable outcome of avoiding surgery. Although the numbers are small, the paper is a useful addition to existing literature and relevant to our circumstances.

Chan and colleague's paper, ${ }^{6}$ on the association of pre-operative oxygen saturation as a predictor of future need for paediatric intensive care in children who undergo supraglottoplasty for laryngomalacia, is a first such study from the UK. This has implications for a number of other procedures undertaken in children with potential airway issues.

Lou and $\mathrm{Lou}^{7}$ reviewed the application of moist agents to the edge of traumatic tympanic membrane perforations; they show that it shortens closure times and improves closure rates. This is not in keeping with traditional teaching to leave traumatic perforations of the eardrum alone. Jellinge et al. ${ }^{8}$ had previously shown a 97 per cent closure rate through a policy of simple watchful waiting.

MUSHEER HUSSAIN
EDWARD FISHER
ROBIN YOUNGS
JONATHAN FISHMAN
Senior Editors

References

1 Harrison L, Corbridge R. Active surveillance management of head and neck paragangliomas: case series and review of the literature. J Laryngol Otol 2017;131:580-4

2 Knudson A. Mutation and cancer: statistical study of retinoblastoma. Proc Natl Acad Sci USA 1971;68:820-3

3 Nordling C. A new theory on cancer-inducing mechanism. $\mathrm{Br} J$ Cancer 1953;7:68-72

4 Moore MG, Netterville JL, Mendenhall WM, Isaacson B, Nussenbaum B. Head and neck paragangliomas: an update on evaluation and management. Otolaryngol Head Neck Surg 2016;154:597-605

5 Persu A, Hamoir M, Grégoire V, Garin P, Duvivier E, Reychler H et al. High prevalence of SDHB mutations in head and neck paraganglioma in Belgium. J Hypertens 2008;26:1395-401

6 Chan S, Siou G, Welch A, Powell S. Predictors for routine admission to paediatric intensive care for post-supraglottoplasty laryngomalacia patients. J Laryngol Otol 2017;131:640-4

7 Lou ZC, Lou ZH. A moist edge environment aids the regeneration of traumatic tympanic membrane perforations. J Laryngol Otol 2017;131:564-71

8 Jellinge ME, Kristensen S, Larsen K. Spontaneous closure of traumatic tympanic membrane perforations: observational study. J Laryngol Otol 2015;129:950-4 